Pediatr. Res. 17: 8-14 (1983)

\title{
Early Ontogeny of Iodocompound-Processing Neural Systems in Rat Brain
}

\author{
FLOY L. CRUTCHFIELD ${ }^{(33)}$ AND MARY B. DRATMAN \\ Veterans Administration Medical Center and The Medical College of Pennsylvania, Philadelphia, Pennsylvania, USA
}

\begin{abstract}
Summary
The distribution and localization of iodocompounds reaching the brain during early development were measured in rat pups nurtured on $\left[{ }^{125} \mathrm{I}\right]$-containing milk from dams receiving daily $\left[{ }^{125} I\right]$-iodide injections. The regimen produced no measurable changes in growth and development of the offspring during the nursing period. Pup brains accumulated labeled iodocompounds at a faster rate than they grew and accumulated protein. The ratio of $\left[{ }^{125}\right]$-iodocompounds in cerebrum relative to skeletal muscle increased progressively from day 11 through day 19. Significant differences in distribution of radioactivity in different brain regions were evident on day 1; developmental progress was associated with significantly different rates of regional accumulation of the isotope. On day 1 only $10 \%$ of the radioactivity in the postnuclear supernatant phase of brain homogenates was particle-bound; at the time of weaning, radioactivity in brain particles accounted for more than 50\%. Growing nerve cell processes and myelin, known to be major targets of early thyroid hormone deficiency or excess, were also the major subcellular sites of $\left[{ }^{125} I\right]$-iodocompound localization in the developing rat brain. Overall, the ontogeny reflected progressive elaboration of iodocompound-processing neural systems resembling those recently recognized in adult brain.
\end{abstract}

\section{Speculation}

Early deficiencies or excesses of aromatic amino acids are known to cause irreversible brain damage, presumably as a result of altered substrate availability for specific neural systems (1). A similar process may account for permanent brain changes resulting from abnormal iodocompound availability during the perinatal period.

Irreversible defects in human brain structure and function occur when hypothyroidism prevails during the perinatal period. Studies conducted to analyze the pathophysiology of this deficiency state in experimental animals reveal derangements in growth of nerve cell processes, myelination, and synaptogenesis (11). The mechanism underlying the stunted neural outgrowth is unknown, although, reduced availability of nerve growth factor (28) and abnormalities in the evolution of protein, carbohydrate, lipid, and nucleic acid metabolism (15) are thought to desynchronize irreversibly the course of neural development.

As compared with the wealth of information documenting the numerous brain abnormalities caused by perinatal hypothyroidism, much less is known about the nature and distribution of iodocompounds reaching the brain during early development (12). To study this aspect of the problem further, rat pups whose dams received daily $\left[{ }^{125} \mathrm{I}\right]$-iodide injections, were nurtured on $\left[{ }^{125} \mathrm{I}\right]$-containing milk, and $\left[{ }^{125} \mathrm{I}\right]$-iodocompounds, (subsequently referred to as iodocompounds*) in brain and other tissues of the offspring were measured from birth to the time of weaning.

\section{MATERIALS AND METHODS}

Rat labeling procedures. Twelve Sprague Dawley rats weighing 250-275 g were received from Charles River Laboratories on the
15 th day of timed pregnancy. They were placed on a low iodine Remington diet (Têklad test diets) and given tap water to drink throughout the period of the experiment. Labeling procedures were carried out as previously described (4). Briefly, eight of the 12 dams were injected from the 18th day of gestation until the time of weaning, with $10 \mu \mathrm{Ci}\left[{ }^{125} \mathrm{I}\right]$-iodide (carrier-free, New England Nuclear) subcutaneously daily, or were provided with an approximately equivalent amount of isotope in the drinking water Litter size was equalized on the day after delivery (called day 1 of postnatal life). Four litters served as nonradioactive controls for the effect of chronic exposure to [ $\left.{ }^{125} \mathrm{I}\right]$ on brain and body growth rates, and also were the source of unlabeled tissues put to a variety of uses as subsequently described.

Preparation of tissues. A predetermined number of nurslings were examined at each time interval. Nurslings were chosen randomly, one each, from within each litter; the litter order was rotated systematically so as to avoid selective depletion or overrepresentation of any one set of siblings. Each nursling was weighed and decapitated immediately after removal from the mother; trunk blood, collected by Pasteur pipette from the decapitation wound, was kept on ice to await clot retraction and subsequent separation by centrifugation. The thyroid areas were dissected en bloc and immediately frozen to await estimation of radioactivity. Brains were dissected quickly on a chilled slab, weighed and then handled according to the object of the analysis. To measure total brain iodocompounds*, radioactivity in uniform aliquot portions of brain homogenates were measured in a refrigerated Packard auto-gamma counter, with efficiency for $\left[{ }^{125} \mathrm{I}\right] \sim$ $70 \%$. For regional distribution studies, brains were quickly dissected into cerebrum, cerebellum, hypothalamus, corpus striatum, and brain stem accoding to the method of Glowinski and Iversen (13). Individual regions were weighed, immediately frozen, and radioactivity was measured directly, without thawing, previous studies having shown that under these conditions, the differences in mass and geometry from one brain region to another had no significant effect on counting efficiency (6). The same methods were used to evaluate radioactivity in serum and in weighed portions of skeletal muscle dissected from the proximal hind limb.

For subcellular distribution studies, freshly dissected brains were immediately immersed in ice cold $0.32 \mathrm{M}$ sucrose (one part brain, nine parts sucrose, wt/v), homogenized, and centrifuged at $1000 \times g$ to remove debris and nuclei. The supernatant phase $\left(S_{1}\right)$ was layered on discontinuous sucrose gradients, centrifuged and the layers separated. All steps were carried out at $4^{\circ} \mathrm{C}$ according to previously described procedures $(6,7)$. Particles were separated from individual fractions after centrifugation in 10-18 volumes isotonic Krebs buffer. As in the case of previous studies in adult animals $(6,7)$, brain cytosol was defined as that portion of $S_{1}$ localized in the upper, $0.32 \mathrm{M}$ sucrose layer of the sucrose density gradient, from which layer microsomal particles were separated by centrifugation at $100,000 \times \mathrm{g}$. Aliquot portions of brain homogenates and subcellular brain fractions and particles were frozen and reserved for further analyses including measurement of radioactivity. Redistribution of radioactivity during the homogenization and separation procedures was evaluated by adding a mixture of labeled iodocompounds $\left(\mathrm{I}^{-}, \mathrm{T}_{4}, \mathrm{~T}_{3}\right)$ to $0.32 \mathrm{M}$ sucrose 
in which brains obtained from unlabeled pups of corresponding age were homogenized. Subsequent separation procedures were performed exactly as described for in vivo labeled brains (7). Protein concentrations of tissues and subcellular components were calculated from measurements made according to the method of Lowry (20) or from nitrogen concentrations, using a Heraeus nitrogen analyzer kindly loaned to us by the Mettler Instrument Corporation.

Data analysis. Because it was accepted at the outset that the sources and amounts of stable iodine entering the milk during the nursing period were unknown and could not be ascertained, all data are expressed as cpm $\times$ unit measurement ${ }^{-1}$, corrected for decay of $\left[{ }^{125} \mathrm{I}\right]$, and not as absolute concentrations of tissue iodine. Rates of iodocompound* accumulation were noted to sort themselves into two distinct phases, the first extending from day 1 until the midpoint of the nursing period (approximately day 10), and the second from midpoint to just before self-weaning at approximately 19 days of age. In each of the two phases, we evaluated changes in body weight ( $\mathrm{g} /$ day), brain weight $(\mathrm{mg} /$ day), brain protein $(\mathrm{mg} / \mathrm{mg}$ tissue/day), and iodocompounds* (cpm/mg tissue) in brain, skeletal muscle, thyroid, and serum. To facilitate comparisons among parameters measured in different units, data for any given day were expressed as ratios of the mean value on day 1 . Slopes of least squares straight line were used to approximate rates of increase in these measurements in each phase. In the case of brain components shown in Figure $8, \%$ of day 4 values was used because day 1 values were highly variable. The method of Newman-Keuls (30) was used to analyze differences among different brain regions, and among different subcellular brain fractions. Overall reproducibility of the results was verified in three separate experiments initiated at different seasons of the year.

\section{RESULTS}

Effects of the labeling regimen on body and brain growth rates. Earlier experiments describing developmental progress of rats chronically receiving $\left[{ }^{125} \mathrm{I}\right]$-labeled milk from dams maintained on a low-iodine diet, revealed that chronic exposure to radioactivity produced changes in body growth rates only measurable at later milestones in development, particularly in males, without any evident defects appearing during the nursing period (4). In the present, as in the previous experiments, body weights were similar in radiation-exposed pups and in the non-irradiated controls through day 19 of life (Fig. 1, upper panel); moreover, chronic $\left[{ }^{125} \mathrm{I}\right]$-treatment produced no discernible changes in brain weights during this period (Fig. 1, lower panel).

Iodocompound ontogeny: overview. Iodocompound* levels in brain, serum, thyroid gland, and skeletal muscle increased through day 11 (phase 1). Thereafter, a different rate of iodocompound* increase was noted until the time of beginning self-weaning, at approximately the 19th postnatal day (phase 2).

In serum, concentrations of radioactivity increased more rapidly in the first phase of the nursing period, whereas in brain, the increase was more rapid in the second phase (Fig. 2). Iodocompound* content of the thyroid gland increased by 54\%/day $(r=$ $0.937)$ and $32 \% /$ day $(r=0.624)$ during phase 1 and 2 respectively, therein resembling the pattern of change in serum, whereas the corresponding values for brain content were 79\%/day $(r=0.976)$ and $145 \% /$ day $(r=0.886)$. During both phases, the average rate of iodocompound* build-up in brain was notably faster than the rate of increase in brain weight or brain protein content (Fig. 3).

In order to compare neural tissue with a relevant somatic tissue, iodocompound* concentrations in cerebrum and skeletal muscle were compared during phase two (31). As seen in Figure 4, the ratio of cerebrum to muscle radioactivity increased slowly (by $4 \% /$ day), but significantly $(P<0.001)$ with time. Because the bloodbrain barrier in the rat becomes more active after about 14 days of postnatal life (for a recent review, see Ref. no. 2), the rate of iodocompound uptake into brain may actually fall during the last phase of the nursing period; however, the progressively greater
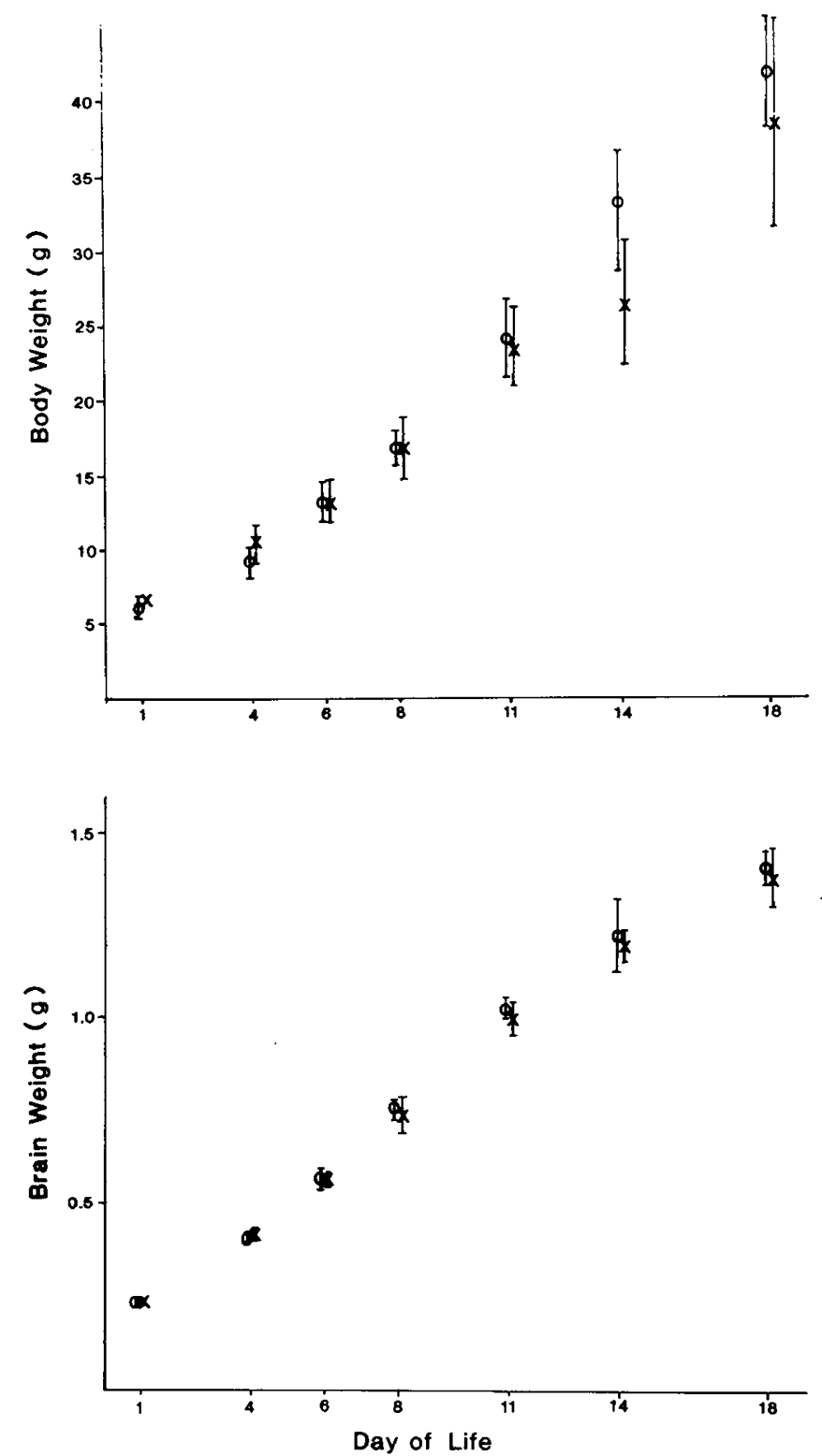

Fig. 1. Effect of chronic exposure to $\left[{ }^{125} I\right]$ on brain and body growth rates of rat pups during the nursing period. Data are expressed as arithmetic means \pm S.D. (O), Offspring of dams receiving low iodine diets plus $\left[{ }^{125} \mathrm{I}\right]$ from 3 days before to 20 days after parturition; (x), offspring reared under the same conditions at the same time but not exposed to $\left[{ }^{125} \mathrm{I}\right] ; n>$ 10 in each group at each time period.

rate of accumulation of radioactivity in brain tissue as compared for example, with skeletal muscle, indicates that local processes within the brain are the most important determinants of its net iodocompound levels.

Ontogeny of iodocompounds* in different brain regions. Previous studies of adult brain have demonstrated nonuniformity of iodothyronine uptake $(6)$, metabolism $(6,18)$, and nuclear binding capacity (26) in different brain regions. In the present studies, we sought to determine whether there were any regional differences in iodocompound* localization in immature brain, and whether regional changes occurred as a function of early development. For this purpose, five distinct anatomic subdivisions of the brain were examined at intervals from the 1st through the 19th day of life. Data set forth in Table 1 reveal that at every time interval studied, iodocompound* concentrations in hypothalamus were significantly lower than in all other regions. Values in all brain regions increased significantly over time. During the second phase, the rate of increase in iodocompounds* varied significantly in each 

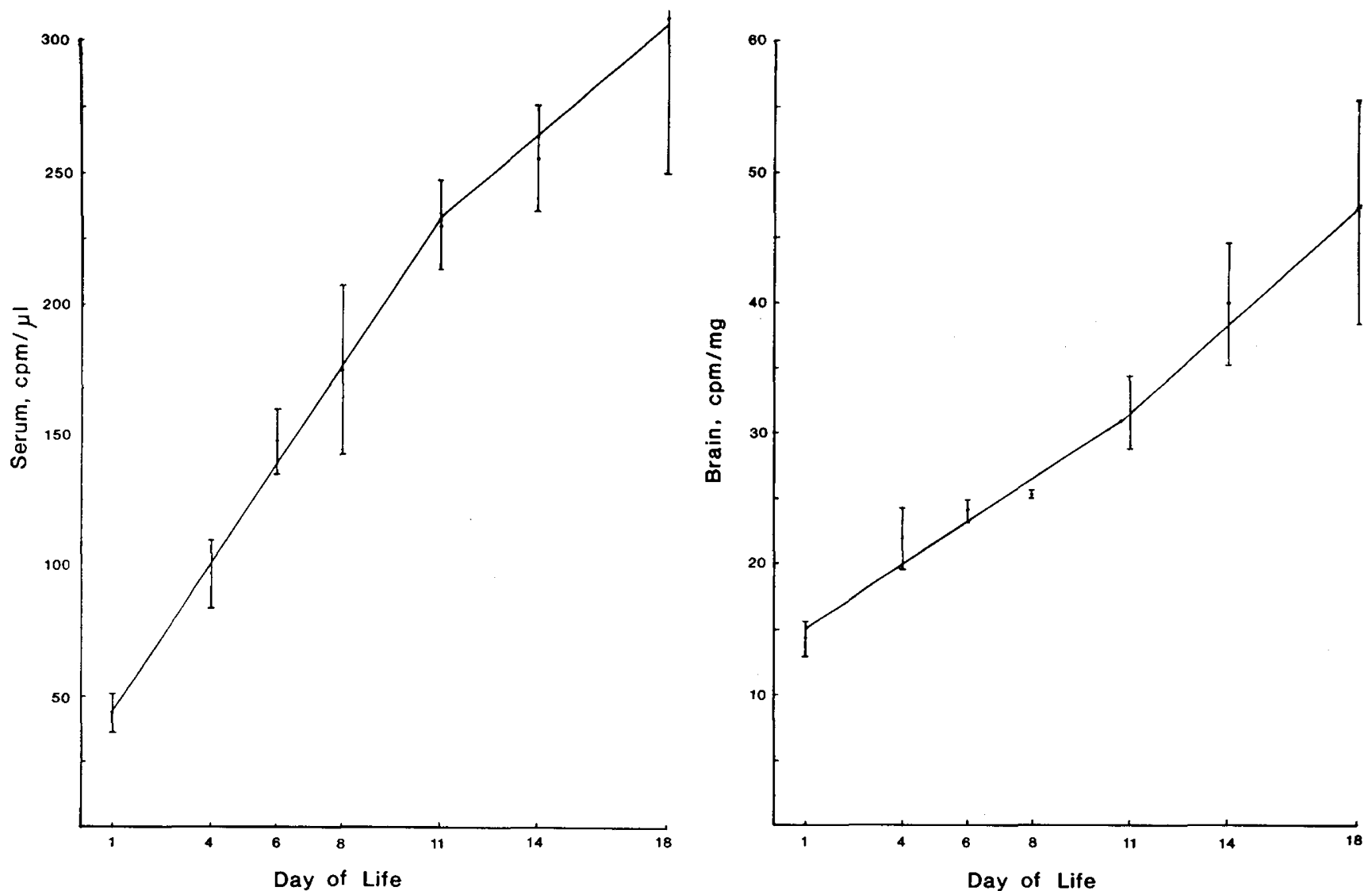

Fig. 2. Concentrations of iodocompounds* in serum and brain of nurslings reared on [ $\left.{ }^{125} \mathrm{I}\right]$-containing milk. Individual data points show arithmetic means $(\mathrm{cpm} / \mu$ liter serum or $\mathrm{cpm} / \mathrm{mg}$ brain) \pm S.D.; $n>3$ at each time period. Note the different scales of the two ordinates.

brain region as compared with all other brain regions $(P<0.001)$. These observations in vivo, are extended by recent in vitro evidence of Kaplan and Yaskoski (19), showing distinctively different maturation-dependent patterns of thyroxine metabolism in rat hypothalamus, cerebellum, and cerebrum.

Although brain increases in mass during the first $3 \mathrm{wk}$ of postnatal life, increasing cytoarchitectural complexity is the most important feature of this phase of brain development (21). Many investigators attribute at least some aspects of evolving brain complexities to the actions of thyroid hormones $(21,25)$; therefore the observed differences of iodocompound* accumulation in different brain regions may be correlated with locally-mediated iodocompound-dependent aspects of neural development.

Ontogeny of iodocompounds* in subcellular brain particles. In view of evidence for differential localization of triiodothyronine in synaptosome-enriched fractions of adult rat brain $(6,7)$, we examined the subcellular distribution of iodocompounds* in $S_{1}$ of brain homogenates during early development. Through the 4 th day of life, subcellular particles in brain $S_{1}$ are reported to exhibit considerable variability in their sedimentation characteristics, leading to difficulties in interpreting results of density gradient separation during the first few days of life $(14,17)$. We too observed that the appearance of the $S_{1}$ gradient profiles and the behavior of particles retrieved at sucrose density interfaces through day 4 were different from those seen in experiments using older rats; however, even on day 1 , it was possible to differentiate between the cytosol fraction $(0.32 \mathrm{M}$ layer of sucrose density gradient after removal of particles sedimenting at $100,000 \times \mathrm{g}$ ) and the total particulate components of $S_{1}$. As seen in Figure 5 , only $10 \%$ of the total $S_{1}$ radioactivity was found in particles on day 1; during successive days the proportion of radioactivity in particles increased daily, amounting to more than $50 \%$ of $S_{1}$ by the 18th day of life (all differences significant, $P<0.001$ ).

After the 4th day, when results of $S_{1}$ fractionation on discontin- uous sucrose density gradients became reproducible from one group of rats to another, clear-cut evidence of a steady evolution in differential localization of labeled iodocompounds in the various brain fractions emerged. Particles present within individual fractions were recovered by centrifugation in a standard manner, after dilution of each separated brain fraction with $0.3 \mathrm{M}$ Krebs phosphate buffer (29). The ratio of radioactivity in the pellet (P) to radioactivity in the supernatant $(\mathrm{S})$ averaged $1.8,2$, and 6 for mitochondria, myelin, and synaptosomes, respectively, whereas $\mathrm{P}: \mathrm{S}$ for microsomal particles did not exceed 1 at any time and averaged only 0.25 . Therefore, without correcting for contamination of the microsomal pellet with cytosol, iodocompound* levels in these particles could not be estimated.

As shown in Figure 6, radioactivity in individual particulate components per $\mathrm{g}$ brain changed in a distinctive manner as the animals matured. Increases in radioactivity were most notable in osmotically sensitive particles sedimenting like synaptosomes and to a lesser extent in osmotically resistant particles behaving like myelin. In particulate fractions enriched in mitochondria the rate of change was much slower and less prominent.

The distribution of iodocompounds* added during homogenization of unlabeled rat brain was measured and compared with that seen in in vivo labeled brains. The results shown in Figure 7 indicate that most of the added radioactivity remained in the microsomal fraction (cytosol plus microsomes) and that only a small \% became associated with myelin, synaptosomes, and mitochondria.

Because the first 3 wk of life encompass a period of rapid increase in nerve terminal density and in degree of myelination (24), it was of interest to evaluate the growth of these components as reflected by their increasing protein content. Figure 8 demonstrates that the rate of accumulation of iodocompounds* and of protein in the cytosol fraction was similar throughout the period of observation, whereas increases in iodocompounds* far out- 
stripped increases in protein content of particles behaving like synaptosomes as well as of those considered to be myelin. Therefore, these ontogenetic studies provide evidence for progressive enrichment of iodocompounds in brain structures (nerve terminals and myelin), which are known to exhibit serious abnormalities as a consequence of perinatal thyroid hormone deficiency.

\section{DISCUSSION}

In the early postnatal phase of growth and development, mammals require certain iodocompounds for normal brain maturation.

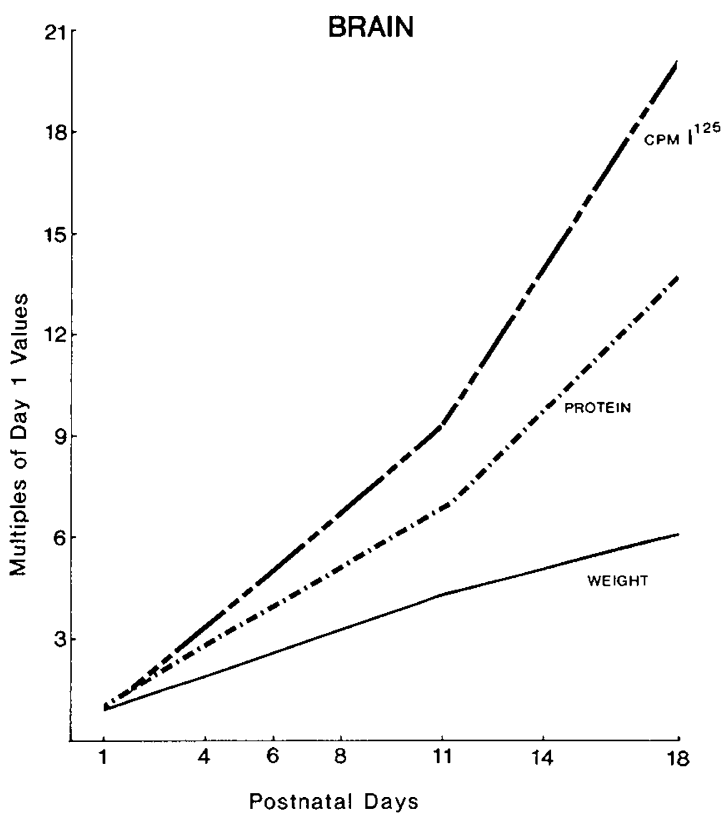

Fig. 3. Increase in wet weight and in content of protein and iodocompounds* in nursling brains during development. Least squares straight lines approximate the relationship of time to individual values in each category expressed as multiples of the respective mean value on day $1 ; n$ $>6$ at each time interval.

\begin{tabular}{|c|c|c|c|}
\hline & \multirow{2}{*}{$\begin{array}{c}\text { Mean day } 1 \\
\text { value } \pm \text { S.D. }\end{array}$} & \multicolumn{2}{|c|}{$\begin{array}{c}\% \text { increase } \times \\
\text { brain }^{-1} \times \text { day }^{-1} \\
(r \text { value })\end{array}$} \\
\hline & & Phase 1 & Phase 2 \\
\hline Wet weight & $0.234 \pm 0.01 \mathrm{~g}$ & $31.6(0.98)$ & $23.2(0.96)$ \\
\hline Protein & $\begin{array}{l}10.8 \pm 0.46 \\
\text { mg protein/brain }\end{array}$ & $57.8(0.95)$ & $96.3(0.97)$ \\
\hline Iodocompounds* & $\begin{array}{l}3334 \pm 287 \\
\mathrm{cpm} / \text { brain }\end{array}$ & $79.4(0.98)$ & $145.2(0.89)$ \\
\hline
\end{tabular}

During gestation, maternal-to-fetal iodine exchange takes place across the placenta. After birth, dietary iodine needs of the nurslings are met through the powerful iodide-concentrating and delivering capacity of the lactating breast (3). Iodide in the circulation of the offspring is subject to further processing in the thyroid gland. The products are ultimately metabolized peripherally according to the requirements of individucal cells and tissues (23). There is no certainty about the nervous system processes mediated or about the role of individual iodocompounds at different stages of normal brain development. All investigators agree that certain iodothyronines are essential but some have suggested that iodide itself (16) as well as iodotyrosines (12) or iodoproteins (9) may play a prenatal role, possibly at a late fetal stage.

Unlike the controversy originally surrounding their action in adult brain, the literature suggests agreement that, at least during a so-called critical period of rat brain development, iodocompounds act directly within the nervous system (27). It seemed worthwhile to gain further information regarding the localization of iodocompounds reaching the brain during this period, because

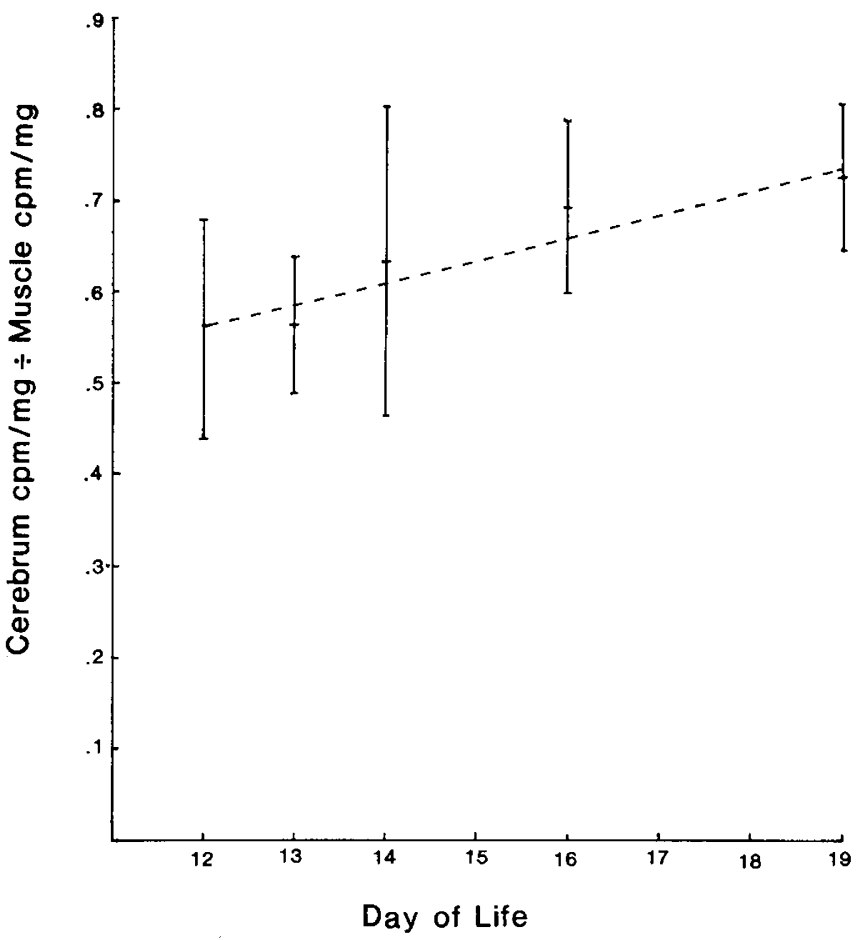

Fig. 4. Iodocompound* concentration in cerebrum relative to skeletal muscle from day 12 through 19 of postnatal life. Values are arithmetic means of the ratios \pm S.D.; $n>4$ at each time interval. Significant change in the ratios over time averaged $4 \% /$ day $(P<0.001)$.

Table 1. Ontogeny of labeled iodocompounds in five regions of rat brain






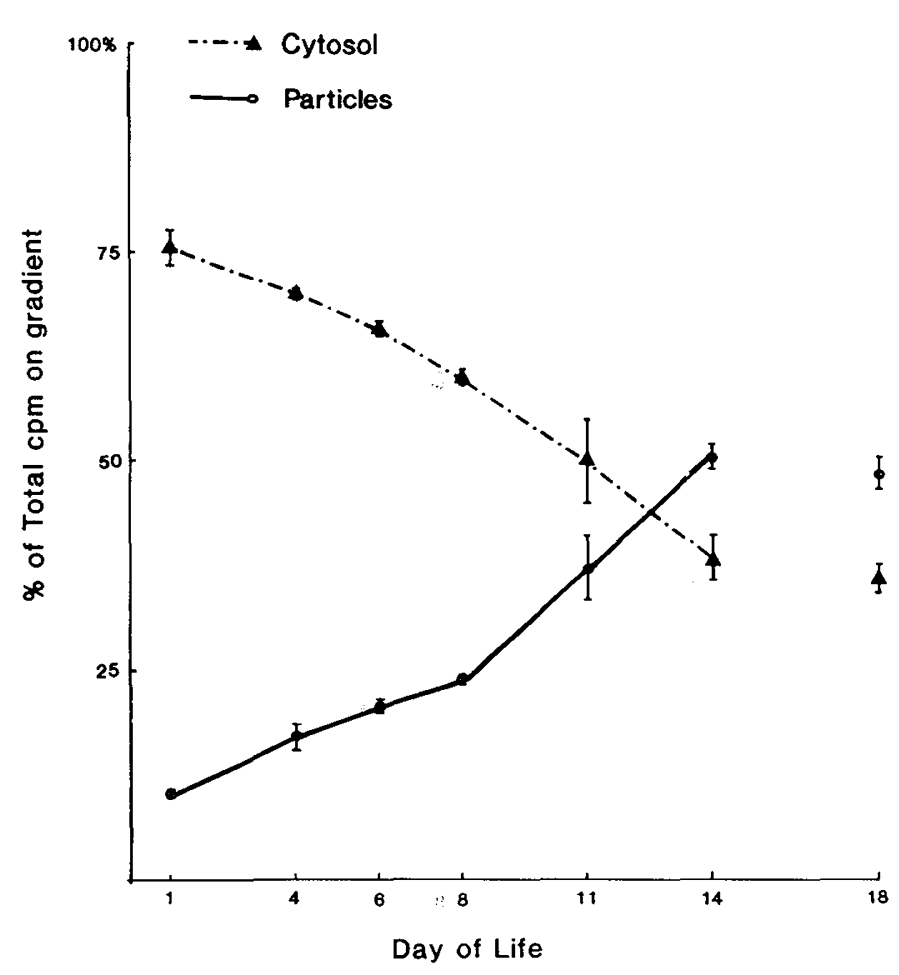

Fig. 5. Developmental changes in localization of iodocompounds* in cytosol versus particles in $S_{1}$ of nursling rat brains. Data are expressed as arithmetic mean \% of total cpm in $S_{1} \pm$ S.D.; $n>3$ at each time interval.

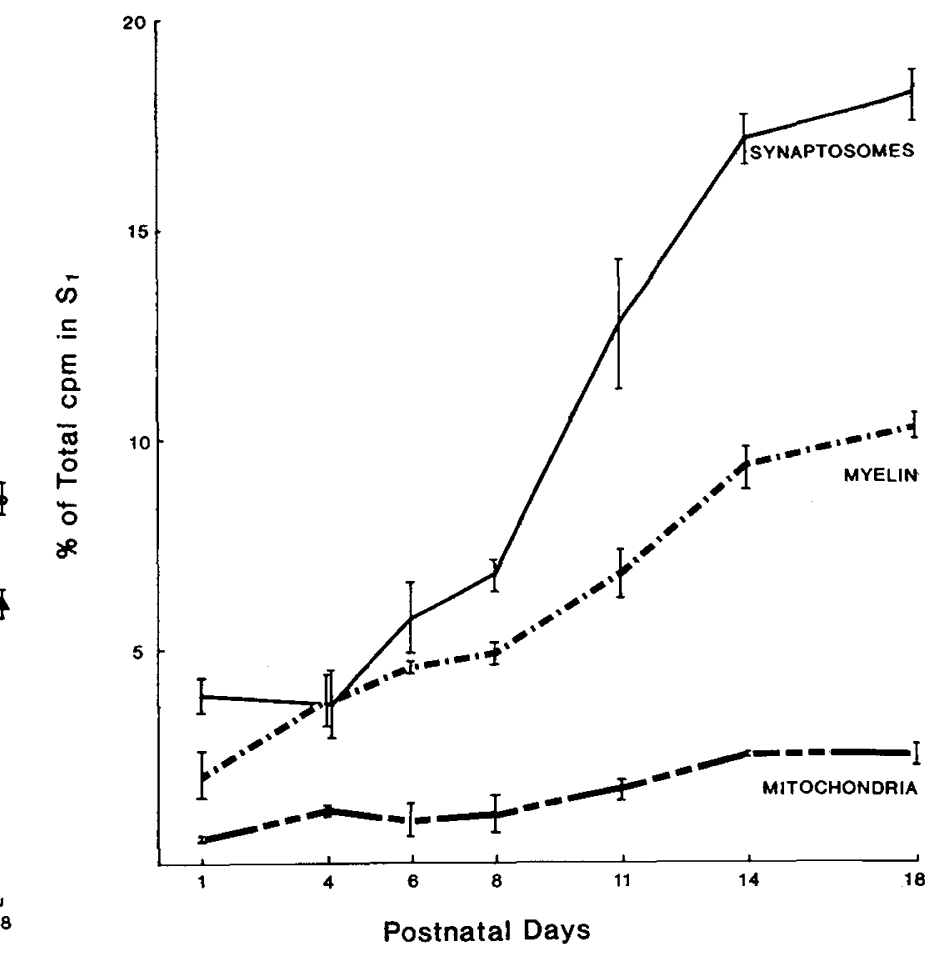

Fig. 6. Iodocompound* localization in synaptosomes, myelin, and mitochondria during development. Data shown are arithmetic mean \% of total cpm in $S_{1} \pm$ S.D. Overall, iodocompounds* in synaptosomes were $675 \pm 31 \%$ and in myelin were $421 \pm 30 \%$ of the value in mitochondria; $n>6$ at each time interval. Differences among the different brain particles were highly significant $(P<0.001)$.
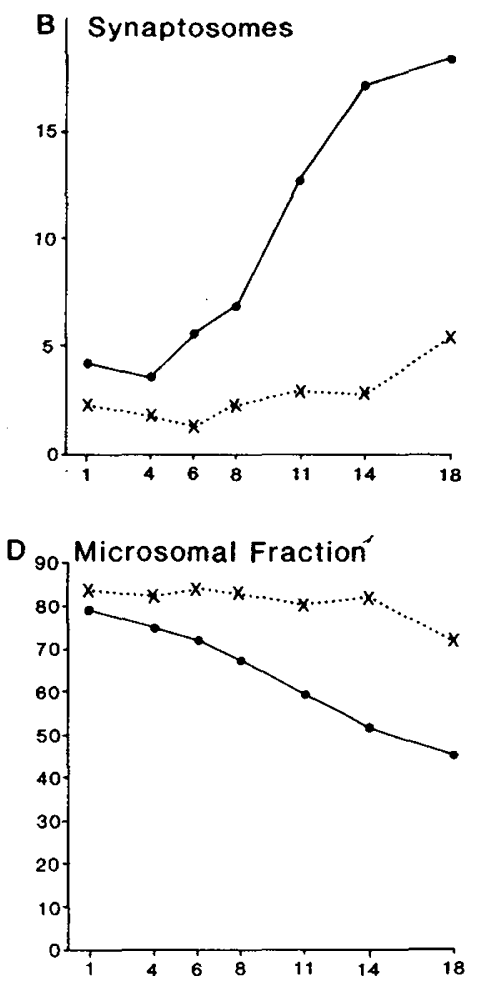

\section{Day of Life}

Fig. 7. Distribution of iodocompounds* added to unlabeled rat brains during homogenization and subcellular separation procedures: comparison with subcellular distribution of label in in vivo labeled brain. Unlabeled rat pup brains (age indicated on abscissae) were homogenized in ice cold 0.32 $M$ sucrose containing a mixture of $\left[{ }^{125} \mathrm{I}\right]$-labeled iodocompounds $\left(\mathrm{I}^{-}, \mathrm{T}_{4}\right.$, and $\left.\mathrm{T}_{3}\right)$. Thereafter, brains with added radioactivity were handled exactly as described for in vivo labeled brains. $(\mathrm{x}---\mathrm{x})$, Unlabeled rat brain and added iodocompounds*; and (- $\bullet$ ), in vivo labeled rat brains. 

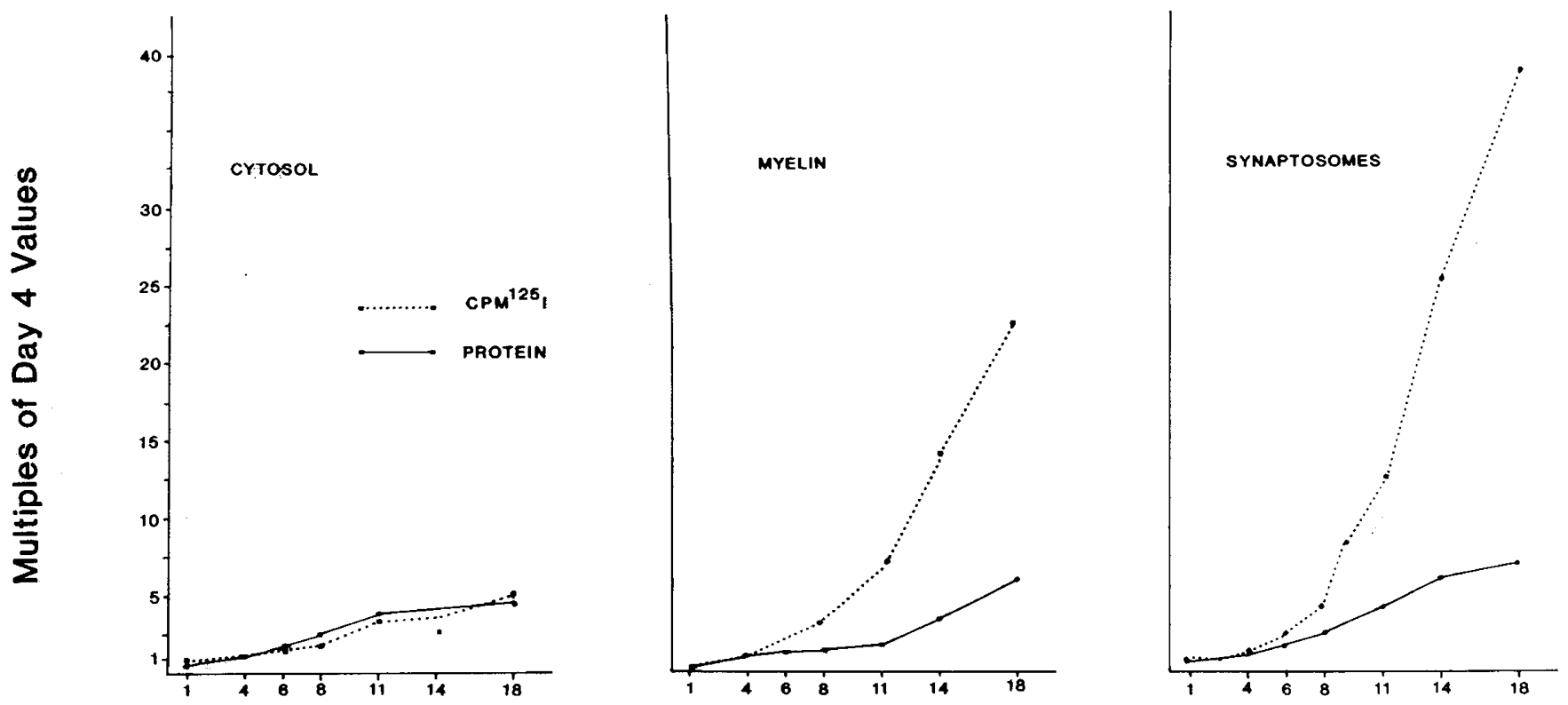

\section{Postnatal Days}

Fig. 8. Accumulation of iodocompounds* and protein in different subcellular components of rat brain during development. Individual data points are means of the values for cytosol, myelin, and synaptosomes per brain, expressed as a function of the respective day 4 values, shown below. Coefficient of variation for protein, $8-21 \%$; for $\left.{ }^{125} \mathrm{I}\right] ; 11-23 \% ; n>3$ at each time interval. After day 4, ratios of protein to [ $\left.{ }^{125} \mathrm{I}\right]$ were significantly different from unity for myelin and synaptosomes $(P<0.001)$ but were at no time significantly different for cytosol. Overall differences among cytosol. myelin and synaptosomes highly significant $(P<0.001)$.

Mean day 4 values/brain \pm S.D.

\begin{tabular}{cccc} 
& Cytosol & Myelin & Synaptosomes \\
\cline { 2 - 4 } cpm & $4969 \pm 623$ & $251 \pm 36$ & $246 \pm 53$ \\
mg Protein & $7.53 \pm 0.146$ & $2.68 \pm 0.052$ & $2.69 \pm 0.052$ \\
\hline
\end{tabular}

such an approach had been fruitful in the case of adult animals $(6,7)$. Use of the relatively nonstressful technique of chronic perinatal ${ }^{[125]}$ I-labeling (4) yielded consistent and coherent measurements of the distribution and relative rates of accumulation of iodocompounds* in different regions and subcellular fractions of the growing brain. Because the time required for equilibration of the labeled iodine compounds with the preexisting iodine compounds was not known, iodocompound* changes noted in these experiments could not be correlated with changes in total iodocompound pools. The conditions of the experiments (low iodine diet, coupled with daily administration of labeled iodide, initiated when fetal thyroid activity is first established) and the known rapid rate of iodocompound turnover during late pregnancy and lactation (10) would facilitate rapid equilibration. Nevertheless, in interpreting our data, we proceeded on the assumption that equilibration had not occurred and made judgments only from comparative measures. For example, it was reasonable to conclude that as compared with brain cytosol, iodocompound-processing nerve endings became progressively more efficient in concentrating and/or in storing iodinated substrate(s) during the course of early postnatal development. This conclusion was based on the observation that the rate of increase of iodocompounds* and protein in brain cytosol was quite similar whereas marked enrichment of iodocompounds* relative to protein in synaptosomes occurred over the same period. Recent observations in vitro are consistent with this interpretation, in that specific synaptosomal triiodothyronine-binding sites are reported to increase in number during the course of early postnatal development (22).

Although only accumulation of total iodocompounds* are reported in this communication, individual iodocompounds* in skeletal muscle, serum, brain as well as in brain regions, subfractions, and particles were measured systematically during the course of the nursing period. The results of those analyses will be described in a separate communication (Crutchfield, F. L., Dratman, M. B. and Gordon, J. T., unpublished observations). Although they served to sharpen the focus of the evidence, they did not alter any of the conclusions inferred from the present data.

On the basis of the observations made in these studies, it appears that the elaboration and maturation of discrete iodocompoundprocessing neural systems is one of the important ontogenetic processes occurring during normal development of the rat brain. The evidence suggests that elements of such systems were already present at birth, in that differential regional iodocompound* localization and metabolism (19) were noted on day 1 of life. These systems then became progressively more defined over the first wk and continued to evolve slowly throughout the rest of the nursing period. At the time of weaning, they resembled but were not yet identical with the fully mature triiodothyronine-processing neural systems previously described in adult rat brain $(5,8)$.

\section{REFERENCES AND NOTES}

1. Andersen, A. E., Rowe, V., and Guroff, G.: The Enduring behavioral changes in rats with experimental phenylketonuria. Proc. Natl. Acad. Sci. USA., 71: 21 (1974).

2. Bradbury, M.: The Concept of a blood-brain barrier. p. 290 (John Wiley and Sons, New York, New York, 1979).

3. Brown-Grant, K.: Extra-thyroidal iodide concentration mechanisms. Physiol. Rev. 41: 189 (1961)

4. Crutchfield, F. L. and Dratman, M. B.: Growth and development of the neonatal rat: particular vulnerability of males to disadvantageous conditions during rearing. Biol. Neonate, 38: 203 (1980).

5. Dratman, M. B.: The Mechanism of thyroxine action, In: Hormonal proteins and peptides, C. H. Li Ed, p. 205 (Academic Press, New York, New York 1978).

6. Dratman, M. B. and Crutchfield, F. L.: Synaptosomal ${ }^{125}$ I-triiodothyronine following intravenous ${ }^{125}$ I-thyroxine. Am: J. Physiol., 235: E638 (1978). 
7. Dratman, M. B., Crutchfield, F. L., Axelrod, J., Colburn, R. W., and Thoa, N.: Localization of triiodothyronine in nerve ending fractions of rat brain. Proc. Natl. Acad. Sci. USA., 73: 941 (1976).

8. Dratman, M. B., Futaesaku, Y., Crutchfield, F. L., Berman, N., Payne, B., Sar, M., and Stumpf, W. E.: lodine-125-labeled triiodothyronine in rat brain: evidence for localization in discrete neural systems. Science, 215: 309 (1982).

9. Dratman, M. B., Richter, M. E., and Lynch, H. A.: Incorporation of thyroxin carbon in protein fractions of Rana catesbiana nervous system, liver and tail. Endocrinology, 86: 217 (1970).

10. DuBois, J. D. and Dussault, J. H.: Ontogenesis of thyroid function in the neonatal rat. Thyroxine $\left(\mathrm{T}_{4}\right)$ and triiodothyronine $\left(\mathrm{T}_{3}\right)$ production rates. Endocrinology, 101: 435 (1977).

11. Eayrs, J. T.: Thyroid hypofunction and the development of the central nervous system. Nature. 172: 403 (1953).

12. Ford, D. H. and Cramer, E. B.: Developing nervous system in relation to thyroid hormones. In: Thyroid hormones and brain development, G. D. Grave, Ed., p 1. (Raven Press, New York, New York, 1977).

13. Glowinski, J. and Iversen, L. L.: Regional studies of catecholamines in rat brain. I. The Disposition of $\left({ }^{3} \mathrm{H}\right)$ norepinephrine $\left({ }^{3} \mathrm{H}\right)$ dopamine and $\left({ }^{3} \mathrm{H}\right)$ DOPA in various regions of the brain. J. Neurochem., 13: 655 (1966).

14. Gonatas, N. K., Autilio-Gambetti, L., Gambetti, P., and Shafer, B.: Morphological and biochemical changes in rat synaptosome fractions during neonatal development. J. Cell Biol., 51: 484 (1971).

15. Grave, G. D.: Thyroid hormones and brain development, p. 1-376 (Raven Press, New York, New York, 1977).

16. Hetzel, B. S. and Querido, A.: Iodine deficiency, thyroid function and brain development, In: Endemic goiter and endemic cretenism. J. B. Stanbury, and B. S. Hetzel, Eds., p. 461 (John Wiley and Sons, New York, New York, 1980).

17. Jones, D. G.: Synapses and synaptosomes. p. 128 (John Wiley and Sons, New York, 1975).

18. Kaplan, M. M. and Yaskoski, K. A.: Phenolic and tyrosyl ring deiodination of iodothyronines in rat brain homogenates. J. Clin. Invest., 66: 551 (1980).

19. Kaplan, M. M. and Yaskoski, K. A.: Maturational patterns of iodothyronine phenolic and tyrosyl ring deiodinase activities in rat cerebrum, cerebellum and hypothalamus. J. Clin. Endocrinol., 67: I208 (1981).

20. Lowry, O. H., Rosebrough, N. J., Farr, A. L., and Randall, R. J.: Protein measurement with the folin phenol reagent. J. Biol. Chem., 193: 265 (195I).

21. Lu, E. J. and Jann Brown, W.: The Developing caudate nucleus in the euthyroid and hypothyroid rat. J. Comp. Neur. 171: 261 (1977).
22. Mashio, Y., Inada, M., Tanaka, K., Ishii, H., Naito, K., Nishikowa, M., and Imura, H.: High affinity binding to synaptosome 3,5,3'-L-triiodothyronine in rat cerebral cortex. Endocrinology, 110: 1257 (1982).

23. Obregon, M. J., Roelfsema, F., Morreale de Escobar, G., and Escobar del Rey, $F .:$ Exchange of triiodothyronine derived from thyroxine with circulating triiodothyronine, as studied in the rat. Clin. Endocrinol. (Oxford), 10: 305 (1979).

24. Rosman, N. P., Malone, M. J., Helfenstein, M., and Kraft, E.: The Effect of thyroid deficiency on myelination of brain. Neurology, 22: 99 (1972).

25. Ruis-Marcos, A., Sanchez-Toscano, F., Escobar del Rey, F., and Morreale de Escobar, G.: Severe hypothyroidism and the maturation of the rat cerebral cortex. Brain Res. 162: 315 (1979)

26. Schwartz, H. L. and Oppenheimer, J. H.: Nuclear triiodothyronine receptor sites in brain: probable identity with hepatic receptors and regional distribution. Endocrinology, 103: 267 (1978).

27. Sokoloff, L.: Action of thyroid hormones and cerebral development. Am. J. Dis. Child, 114: 498 (1967)

28. Walker, P., Weil, M. L., Weichsel, M. E., and Fisher, D. A.: Effect of thyroxine on nerve growth factor concentration in neonatal mouse brain. Life Sci., 28 : 1777 (1981).

29. Whittaker, V. P., Michaelson, I. A., and Kirkland, R. J. A.: The Separation of synaptic vesicles from nerve-ending particles ('synaptosomes'). Biochem. J., 90 : 293 (1964)

30. Winer, B. J.: Statistical principles in experimental design. McGraw-Hill, New York, p. 105 (1962).

31. During the early postnatal period, samples of skeletal muscle removed from the hind limb were frequently contaminated with heavily labeled osteogenetic elements, leading to wide variability in iodocompound* concentration from one muscle sample to another.

32. We appreciate Dr. Lester van Middlesworth's advice about the labeling techniques used in these experiments, and thank Ms. Effie Erlichman for expert technical assistance.

33. Requests for reprints should be addressed to: Dr. Floy L. Crutchfield, Veterans Administration Medical Center, Research Wing, Room A216R, Philadelphia, PA 19104

34. This research was supported by the Veterans Administration Medical Research Service, and NIMH Grant \#MH29549.

35. Received for publication August 19, 1981

36. Accepted for publication April 19, 1982. 